\title{
Flora da Paraíba, Brasil: Tillandsia L. (Bromeliaceae) ${ }^{1}$
}

\author{
Ricardo Ambrósio Soares de Pontes ${ }^{2}$ \& Maria de Fátima Agra ${ }^{3}$
}

\section{Resumo}

(Flora da Paraíba, Brasil: Tillandsia L. (Bromeliaceae)) Este trabalho teve como objetivo elaborar o tratamento taxonômico das espécies do gênero Tillandsia L. ocorrentes no estado da Paraíba, como parte do projeto "Flora Paraibana". Foram identificadas 12 espécies para o estado: T. bulbosa Hook.f., T. gardneri Lindl., T. juncea (Ruíz \& Pav.) Poir., T. kegeliana Mez, T. loliacea Schult. \& Schult. f., T. polystachia L., T. recurvata (L.) L., T. streptocarpa Baker, T. stricta Sol. ex Sims., T. tenuifolia var. surinamensis (Mez) L.B.Sm., $T$. usneoides (L.) L. e T. globosa Wawra var. globosa. Dentre estas, T. bulbosa e T. stricta são referidas pela primeira vez para o estado.

Palavras-chave: Tillandsioideae, taxonomia, flora, Nordeste do Brasil.

\section{Abstract}

(Flora of Paraiba, Brazil: Tillandsia L. (Bromeliaceae)) The present work constitutes a taxonomic treatment of the genus Tillandsia L. in the State of Paraíba as part of the project "Flora Paraibana". Twelve taxa were identified occurring in this area: T. bulbosa Hook.f., T. gardneri Lindl., T. juncea (Ruíz \& Pav.) Poir., $T$. kegeliana Mez, T. loliacea Mart. ex Schult.f., T. polystachia L., T. recurvata (L.) L., T. streptocarpa Baker, $T$. stricta Sol. ex Sims., Tillandsia tenuifolia var. surinamensis (Mez) L.B.Sm., T. usneoides (L.) L. and Tillandsia globosa Wawra var. globosa. Of these, two species (T. bulbosa and T. stricta) constitute the first reference for Paraíba.

Key-words: Tillandsioideae, taxonomy, flora, Northeastern Brazil.

\section{INTRODUÇÃo}

Bromeliaceae está representada por 56 gêneros (Grant \& Zijlstra 1998) e aproximadamente 3.270 espécies (Luther 2000), sendo Tillandsia um dos gêneros mais diversificados, compreendendo cerca de 620 espécies (Luther 2000), com distribuição na América tropical e subtropical, desde o sul dos Estados Unidos até o norte da Argentina. O gênero caracteriza-se por apresentar plantas herbáceas, saxícolas, rupícolas ou epífitas, com folhas polísticas ou dísticas, inermes, inflorescências em espigas de onde emergem flores com corolas coloridas e vistosas, protegidas por brácteas, ou raro com flores isoladas.

Tillandsia é um dos gêneros de Bromeliaceae mais representados na caatinga. Entretanto, poucos são os estudos que revelam a diversidade do gênero neste ecossistema.
Para a Região Nordeste, Barbosa et al. (1996) referiram a ocorrência de 15 espécies. Wanderley \& Sousa (2002) registraram a presença de 14 espécies para o ecossistema caatinga. A pouca diversidade das Bromeliaceae representada nos levantamentos florísticos, no âmbito da caatinga, foi referida por Leme (1993) como "uma lista repetitiva das espécies mais conhecidas".

As informações sobre as espécies de Tillandsia na Paraíba são escassas, somente encontradas em citações pontuais de Smith (1955) e Smith \& Downs (1977), que referiram a presença de sete espécies.

Do ponto de vista econômico, o gênero Tillandsia destaca-se por seu valor ornamental, sendo muitas espécies comercializadas em floriculturas de todo o mundo, como Tillandsia cyanea (A. Dietr.) E. Morren, T. xerographica Rohweder, T.

Artigo recebido em 01/2005. Aceito para publicação em 08/2005

${ }^{1}$ Parte da monografia de graduação do primeiro autor. Trabalho premiado como melhor monografia de estudos em Bromeliaceae 2002-2003, pela Sociedade Brasileira de Bromélias (SBBr).

${ }^{2}$ Pós-Graduando da Escola Nacional de Botânica Tropical, Instituto de Pesquisa do Jardim Botânico do Rio de Janeiro. ricardoapontes@jbrj.gov.br

${ }^{3}$ Autor para correspondência: Maria de Fátima Agra. Laboratório de Tecnologia Farmacêutica, Universidade Federal da Paraíba, Caixa Postal 5009, CEP. 58051-059, João Pessoa, PB, Brasil. mfagra@yahoo.com.br 
aeranthos (Loisel.) L. B. Sm., entre outras. Na Paraíba, várias espécies nativas são comercializadas em floriculturas, como $T$. gardneri, $T$. tenuifolia e $T$. polystachia. Outras espécies são utilizadas na confecção de arranjos florais, como T. usneoides, cujas plantas são encontradas em grandes estoques nas floriculturas do estado (obs. pessoal).

Este trabalho teve como objetivo elaborar o tratamento taxonômico do gênero Tillandsia na Paraíba, contribuindo para um maior conhecimento da diversidade da flora paraibana (Agra \& Barbosa 1996; Cabral \& Agra 1999; Rocha \& Agra 2001, 2002; Pontes \& Agra 2001).

\section{Material e Métodos}

Área de Estudo - O estado da Paraíba localiza-se na porção oriental do Nordeste do Brasil, entre os meridianos de $34^{\circ} 45^{\prime} 54^{\prime \prime}$ e $38^{\circ} 45^{\prime} 45^{\prime \prime}$ longitude Oeste, e entre os paralelos de 602'12" e 8¹9'18" latitude Sul. Segundo Carvalho \& Carvalho (1985), vários tipos de vegetações ocorrem no estado, dependendo dos compartimentos morfológicos e suas condições ambientais: vegetação pioneira, campos e matas de restingas, manguezais, mata úmida (mata perenifólia costeira ou mata atlântica, mata perenifólia de altitude ou mata de brejos), tabuleiros, agreste, mata sub-caducifólia de transição, matas serranas e caatinga.

Coletas e Identificações - Realizaram-se coletas e observações de campo, relativas à morfologia, fenologia e ecologia, em diversas áreas do estado. As identificações foram realizadas com base na análise dos caracteres reprodutivos e vegetativos, com auxílio da bibliografia especializada (Mez 1891-1894; Smith 1955; Smith \& Downs 1977). Adicionalmente também foram realizadas análises comparativas com espécimes dos seguintes herbários: JPB, EAN, IPA e UFP (siglas segundo Holmgren et al. 1990).

Os estudos morfológicos e as ilustrações foram realizados com auxílio de estereomicroscópio e câmara-clara, Zeiss. A morfologia do estigma seguiu a classificação de Brown
\& Gilmartin (1989) e as descrições foram elaboradas utilizando-se as terminologias encontradas em Radford et al. (1974).

Os dados de distribuição geográfica, fenologia e ecologia de cada espécie foram retirados das etiquetas das exsicatas, complementados com observações de campo.

Tillandsia globosa var. globosa citada para a Paraíba por Smith \& Downs (1977), com base na coleção Foster 2415, depositada no Herbário do Smithsonian Institution (US), não foi descrita no presente tratamento, por não ter sido mais coletada na área.

\section{Resultados}

Tillandsia L., Sp. pl. 286. 1753.

Ervas caulescentes até caules inconspícuos, saxícolas, rupícolas ou epífitas. Folhas rosuladas ou distribuídas ao longo do caule, polísticas ou dísticas, imbricadas, margens inteiras, crassas ou não; lâminas estreitamente liguladas, lanceoladas ou linear-filiformes; indumento pouco a fortemente cinérea, escamas simétricas ou assimétricas, de contorno arredondado, triangular ou irregular. Escapo desde bem distinto até ausente. Inflorescência em espiga, simples ou ramificada, com flores dísticas ou polísticas, raramente reduzidas a uma única flor. Bráctea floral conspícua, elíptica, elíptico-lanceolada ou oval-lanceolada. Flores sésseis, eretas. Sépalas simétricas, livres ou as posteriores soldadas, carenadas ou ecarenadas. Pétalas livres, lilases, amarelas, róseas, brancas, azuis ou verde-amareladas, unha estreita, linear a suborbicular. Estames 6, inclusos ou exsertos; filetes cilíndricos ou complanados; anteras com deiscência rimosas, amarelas ou negras. Ovário súpero, glabro; óvulos numerosos, caudados; estilete cilíndrico; estigma simples-ereto ou espiral-conduplicado. Fruto capsula septicida; sementes cilíndricas ou fusiformes, com apêndices basais, plumosos e brancos.

O gênero Tillandsia está representado na Paraíba por 12 espécies, pertencentes a quatro subgêneros de acordo com o tratamento infragenérico de Smith \& Downs (1977). O 
subgênero Anoplophytum está representado por quatro espécies, T. gardneri, T. stricta, $T$. tenuifolia var. surinamensis e T. globosa var. globosa. Tillandsia subgênero Tillandsia possui quatro espécies, T. bulbosa, T. juncea, T. kegeliana e T. polystachia. Para o subgênero Diaphoranthema foram registradas três espécies, $T$. loliacea, $T$. recurvata e $T$. usneoides. O subgênero
Phytarrhiza está representado apenas por $T$. streptocarpa. Representantes de Tillandsia têm sido encontrados nos remanescentes de mata atlântica, incluindo "brejos de altitudes", e no semi-árido (agreste, matas serranas e caatinga), em elevações que variam de 10 a $1.200 \mathrm{~m}$ de altitude, ocorrendo como epífitas ou rupícolas, sendo algumas vezes, a forma de vida, facultativas para um mesmo táxon.

\section{Chave para identificação das espécies de Tillandsia}

1. Estames exsertos.

2. Ovário elíptico a oval-elíptico, cerca de $5 \mathrm{~mm}$ compr.

3. Folhas com bainhas indistintas; estames e estiletes $4,5 \mathrm{~cm}$ compr. .... 6. T. polystachia

$3^{\prime}$. Folhas com bainhas distintas; estames e estiletes menores que $3,5 \mathrm{~cm}$.

4. Inflorescência não complanada; sépalas carenadas; cápsula até $3,6 \mathrm{~cm}$ compr.

1. T. bulbosa

4’. Inflorescência complanada; sépalas ecarenadas; cápsula maior que $4 \mathrm{~cm}$ compr.

4. T. kegeliana

2’. Ovário cônico, cerca de $8 \mathrm{~mm}$ compr.

3. T. juncea

$1^{\prime}$. Estames inclusos.

5. Folhas polísticas; escapo densamente bracteado.

6. Brácteas do escapo longo-caudadas com o ápice espiralado; lâmina com pétala orbicular; estigma espiral-conduplicado

8. T. streptocarpa

6'. Brácteas do escapo curto-caudadas com o ápice ereto; pétala com lâmina espatulada, linear a suborbicular; estigma simples-ereto.

7’. Estames menores que $5 \mathrm{~mm}$ compr.; ovário menor que 1,5 mm compr.; estilete diminuto, ca. $1 \mathrm{~mm}$ compr.

5. T. loliacea

7'. Estames maiores que $8 \mathrm{~mm}$ compr.; ovário de 3 a 4 mm compr.; estilete evidente, acima de $7 \mathrm{~mm}$ compr.

8. Folhas fortemente cinéreas com escamas densas; inflorescência pêndula; sépalas ovais; estilete até $8 \mathrm{~mm}$ compr.

$8^{\prime}$. Folhas verdes com escamas laxas; inflorescência ereta; sépalas lanceoladas, elípticas a elíptico-lanceoladas; estilete acima de $1 \mathrm{~cm}$ compr.

9. Pétalas $1,2 \mathrm{~cm}$, alvas; estames soldados à unha da pétala

10. T. tenuifolia var. surinamensis

9’. Pétalas $1,7 \mathrm{~cm}$, púpuras; estames soldados na base do ovário

9. T. stricta

5'. Folhas dísticas; escapo ausente, ou quando presente com apenas uma bráctea.

10. Raízes e escapo presentes; flores em espiga; pétalas lilases; ovário ca. $3 \mathrm{~mm}$ compr.

7. T. recurvata

10'. Raízes e escapo ausentes; flores isoladas; pétalas esverdeadas; ovário ca. 1,5 mm compr. 11. T. usneoides 
1. Tillandsia bulbosa Hook., Exot. Fl. 3: 173. 1826.

Fig. 4 p-s

Planta 12-18 cm alt., epífita; caule inconspícuo; raízes presentes, rígidas. Folhas polísticas, verdes, imbricadas, margens onduladas; lâmina 3-16 cm compr., linearfiliforme, verde, ápice filiforme; bainha 1,8-2 $\times 1,7-1,8 \mathrm{~cm}$, elíptica, muito distinta, cinérea. Escapo ereto ou recurvo, $8-10 \mathrm{~cm}$; brácteas oval-lineares, levemente filiformes no ápice, 7$8 \times 0,2-3 \mathrm{~cm}$ compr., imbricadas, verdes. Inflorescência em espiga simples, excedendo as folhas, 4-7 cm compr.; brácteas florais ca. $2 \times 1,7 \mathrm{~cm}$, elípticas, verdes, ápice apiculado, ultrapassando as sépalas. Sépalas subconatas, $1,7-1,8 \times 0,3-0,4 \mathrm{~cm}$, elípticas, carenadas, glabras, ápice agudo. Pétalas ca. $3 \times 0,5 \mathrm{~cm}$, elíptico-lanceolada, ápice sub-agudo; estames exsertos, ca. 3,4 cm compr.; filetes compressos; ovário ca. $5 \mathrm{~mm}$ compr., elíptico, trígono; estilete 2,5-2,6 cm compr., cilíndrico; estigma espiral-conduplicado. Cápsula 3,5-3,6 cm compr., valvas retorcidas na deiscência; sementes $2-2,5 \mathrm{~mm}$ compr., apêndices plumosos 2-2,3 cm compr.

Tillandsia bulbosa possui ampla distribuição na América Central, Caribe e América do Sul. No Brasil ocorre nas Regiões Norte, Nordeste e Sudeste. Foi citada para o Nordeste por Smith \& Downs (1977) para os estados de Pernambuco, Alagoas e Bahia, sendo aqui a sua primeira referência para o estado da Paraíba, onde foi encontrada somente em uma área de mata costeira. Foi coletada com flores em agosto e frutos em setembro.

Material examinado: BRASIL. PARAÍBA: Mamanguape, Estação Ecológica Capim Azul, 18.VIII.1988, fl., L. P. Félix \& A. Miranda s.n. (JPB 15659); 5.IV.1989, L. P. Félix \& A. Miranda 9344 (JPB); Reserva Biológica Guaribas, Área II, 28.IX.2001, fr., M. S. Pereira s.n. (JPB 28365).
2. Tillandsia gardneri Lindl., Bot. Reg. 28: t. 63. 1842.

Fig. $1 \mathrm{f}-1$

Planta 12-20 cm alt., epífita; caule inconspícuo; raízes presentes, rígidas. Folhas polísticas, fortemente cinéreas, imbricadas, as inferiores reflexas, as superiores eretas; lâmina $12-16,5 \times 1,4-1,6 \mathrm{~cm}$, triangular, ápice longamente-atenuado; bainha $4 \mathrm{~mm}$ compr., indistinta. Escapo pêndulo, 7-9 cm compr.; brácteas elíptico-lanceoladas, $12-16 \mathrm{~cm}$ compr., curto caudada, imbricada, cinérea. Inflorescência em espiga, 3-6-ramos, subglobosos a globosos, não excedendo as folhas; brácteas florais cinéreas, 2,4-2,6 × 1,1$1,2 \mathrm{~cm}$, oval-elípticas, carenadas, ápice cuspidado, ultrapassando as sépalas. Sépalas conatas na base, ca. $1,2 \times 0,7 \mathrm{~cm}$ compr., ovais, carenatas, glabras, subcuspidatas. Pétalas ca $1,6 \times 0,3 \mathrm{~cm}$ compr., espatulada, ápice arredondado; estames inclusos, ca. $8,5 \mathrm{~mm}$ compr., soldados na base do ovário; filetes fortemente plicados; ovário ca. $4 \mathrm{~mm}$ compr., oval; estilete 7,5-8 mm compr., cilíndrico; estigma simples, ereto. Cápsula 3-3,6 cm compr.; valvas retas na deiscência; sementes 2,5-3 mm compr., apêndices $2,4-2,8 \mathrm{~cm}$ compr., plumosos.

Espécie da América do Sul, ocorrendo na Colômbia e no Brasil, onde é encontrada desde o Piauí até o Rio Grande do Sul (Smith \& Downs 1977). Na Paraíba, T. gardneri tem sido encontrada em remanescentes de mata atlântica, matas serranas e na caatinga. Floresce em agosto e frutifica em setembro.

Material examinado: BRASIL. PARAÍBA: Gurinhém, Serra do Cajá, 27.VIII.1998, fl., G. S. Baracho et al. s.n. (UFP 21985); Mamanguape, Estação Ecológica, 17.VIII.1988, L. P. Félix \& A. Miranda s.n. (JPB 15660); Maturéia, Pico do Jabre 18.I.1997, M. F. Agra et al. 3907 (JPB); 27-29.IX.1997, fr., M. F. Agra et al. 4225 (JPB); 27-29.IX.1997, fr., M. F. Agra et al. 4229 (JPB); 27-29.X.1997, M. F. Agra et al. s.n. (JPB 21995); 18.I.1997, Agra et al. 3.907 (JPB). 

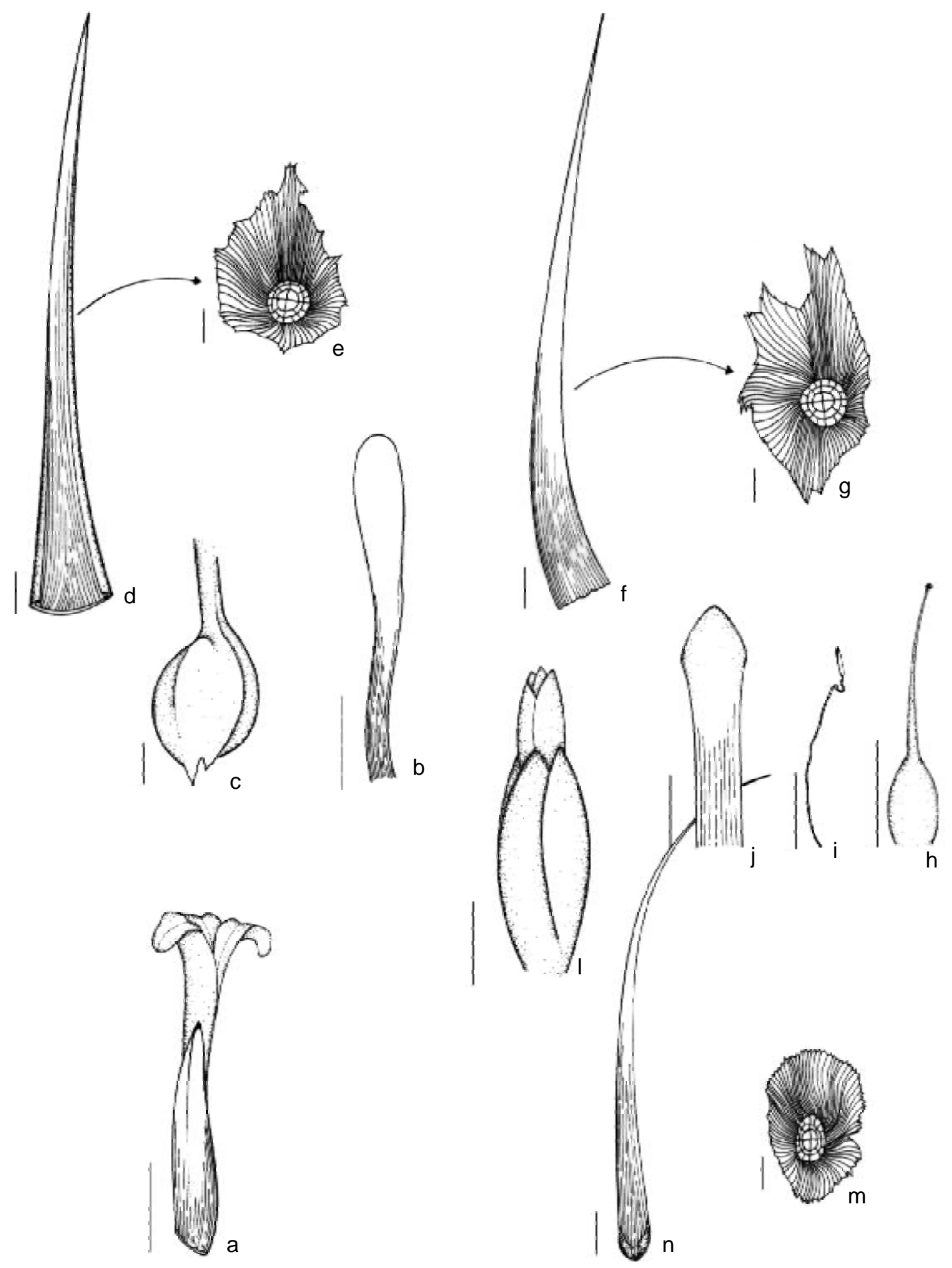

Figura 1 - Tillandsia tenuifolia var. surinamensis - a. flor; b. pétala; c. ovário; d. folha; e. escama (Agra 4564). T. gardneri - f. folha; g. escama; h. gineceu; i. estame plicado; j. pétala; 1. flor (Agra 4225). T. stricta - m. escama; n. folha (Félix s.n., JPB 15660). (Escalas: d, f, $\mathrm{n}=1 \mathrm{~cm} ; \mathrm{a}, \mathrm{b}, \mathrm{h}, \mathrm{i}, \mathrm{j},=5 \mathrm{~mm} ; \mathrm{c}=1 \mathrm{~mm} ; \mathrm{l}=2 \mathrm{~cm} ; \mathrm{e}, \mathrm{g}, \mathrm{m}=83 \mu \mathrm{m}$ ). 
3. Tillandsia juncea (Ruíz \& Pav.) Poir., Encycl. Suppl. 5: 309. $1817 . \quad$ Fig. 4 a-d

Planta 35-40 cm alt., epífita; caule inconspícuo; raízes presentes, rígidas. Folhas laminares, polísticas, cinéreas, imbricadas; lâmina 15-32 cm compr., lanceoladas, lepidota, ápice longo-atenuado; bainha $0,5-1 \mathrm{~cm}$ compr., pouco distinta da lâmina. Escapo ereto, 14-17 cm compr., robusto; brácteas elípticolanceoladas, $8-10 \times 1-1,2 \mathrm{~cm}$, imbricadas, cinéreas. Inflorescência em espiga simples, não excedendo as folhas, $8-9 \mathrm{~cm}$ compr.; brácteas florais 2-2,5 × 1,2-1,4 cm, ovais, ápice agudo a acuminado, cinéreas, ultrpassando as sépalas. Sépalas conatas, $1,6-1,8 \times 0,35-0,45$ $\mathrm{cm}$, elíptico-lanceoladas, carenadas, glabras, acuminadas. Pétalas ca. 3,0 × 0,5 cm compr., lanceolada, ápice agudo; estames exsertos, ca. $1,3 \mathrm{~cm}$ compr., soldados na base do ovário; filetes cilíndricos; ovário ca. $8 \mathrm{~mm}$ compr., cônico; estilete $2,8 \mathrm{~cm}$ compr., cilíndrico; estigma espiral-conduplicado. Cápsula 2,5-2,7 cm compr., valvas retas na deiscência; sementes 2-2,2 mm compr., apêndices 2,2$2,5 \mathrm{~cm}$ compr., plumosos.

Espécie com ampla distribuição, sendo encontrada desde o México até a Bolívia (Smith \& Downs 1977). T. juncea é rara na área de estudo, só conhecida de duas coletas, sendo uma no agreste e a outra em "brejo de altitude". Floresce e frutifica em junho.

Material examinado: BRASIL. PARAÍBA: Areia, 15.VI.1999, fr., G. S. Baracho \& J. A. Siqueira-Filho 839 (UFP). Gurinhém, s.d., fl., G. S. Baracho et al. 748 (UFP).

\section{Tillandsia kegeliana Mez, in DC., Monogr.} Phan. 9: 725. 1896.

Fig. 4 1-o

Planta 11-14 cm alt., epífita; caule inconspícuo; raízes presentes, rígidas. Folhas polísticas, cinéreas, as internas arroxeadas, imbricadas, reflexas; lâmina 6-8 8 0,5-0,8 cm, revoluta, cinérea, ápice aciculado a longo atenuado; bainha 2,3-4,0 × 2,2-3,2 cm, ovalalada, distinta, cinérea. Escapo ereto, 4-7 cm compr., bracteado; brácteas do escapo, elípticas a oval-elípticas, $2,5-2,7 \times 0,5-0,8 \mathrm{~cm}$, imbricadas, ápice sub-caudado. Inflorescência em espiga simples, complanada, excedendo as folhas, 4,5-6,5 cm compr.; brácteas florais 2,63,3 × 1,3-2,1 cm, ovais a oval-elípticas, ápice apiculado, vermelho-alaranjadas, as inferiores fortemente carenatas, envolveldo as sépalas. Sépalas sub-conatas, 2,3-2,5 × 0,9-1 cm, elípticas, ecarenadas, glabras, ápice apiculado. Pétalas ca. $3 \times 0,4 \mathrm{~cm}$, violetas (AndradeLima!, 67-4998), elíptica, ápice agudo; estames exsertos, ca. 3,2 cm compr., amarelos, soldados na base do ovário; filetes compressos, delgados; ovário ca. 5 mm compr., oval-elíptico; estilete 2,4-2,6 cm compr., cilíndrico; estigma espiral-conduplicado. Cápsula $5 \mathrm{~cm}$ compr., valvas retorcidas na deiscência, interiormente enegrecida, com as bordas mais claras; sementes não vistas.

Tillandsia kegeliana é uma espécie rara na Paraíba, conhecida de apenas três coleções, sendo a mais antiga, Andrade-Lima de 674.998, coletada em área de mata atlântica. As outras coleções são mais recentes, após 35 anos, durante a realização deste trabalho, uma em um remanescente de mata semicaducifólia (R. A. Pontes 5) e outra em brejo de altitude (R. A. Pontes 109). Wanderley \& Sousa (2002) registraram a ocorrência de $T$. kegeliana para a caatinga paraibana, entretanto, com base no material examinado para o estado, verificou-se que esta espécie ocorre somente em remanescentes de mata atlântica e mata semicaducifólia. Foi observada com flores em maio e com frutos em maio e dezembro.

Material Examinado: BRASIL. PARAÍBA: BR-101, km 78 de Goiana (PE) em direção a João Pessoa (PB), 1.V.1967, fl. fr., $D$. Andrade-Lima 67-4998 (IPA); Lagoa Seca, fazenda Ipuarana, rodovia PB-097, 6.XII.2000, fr., R. A. Pontes 5 (JPB); Areia, Reserva Ecológica Mata do Pau-Ferro, 4.X.2004, est., R. A. Pontes et al. 109 (JPB). 


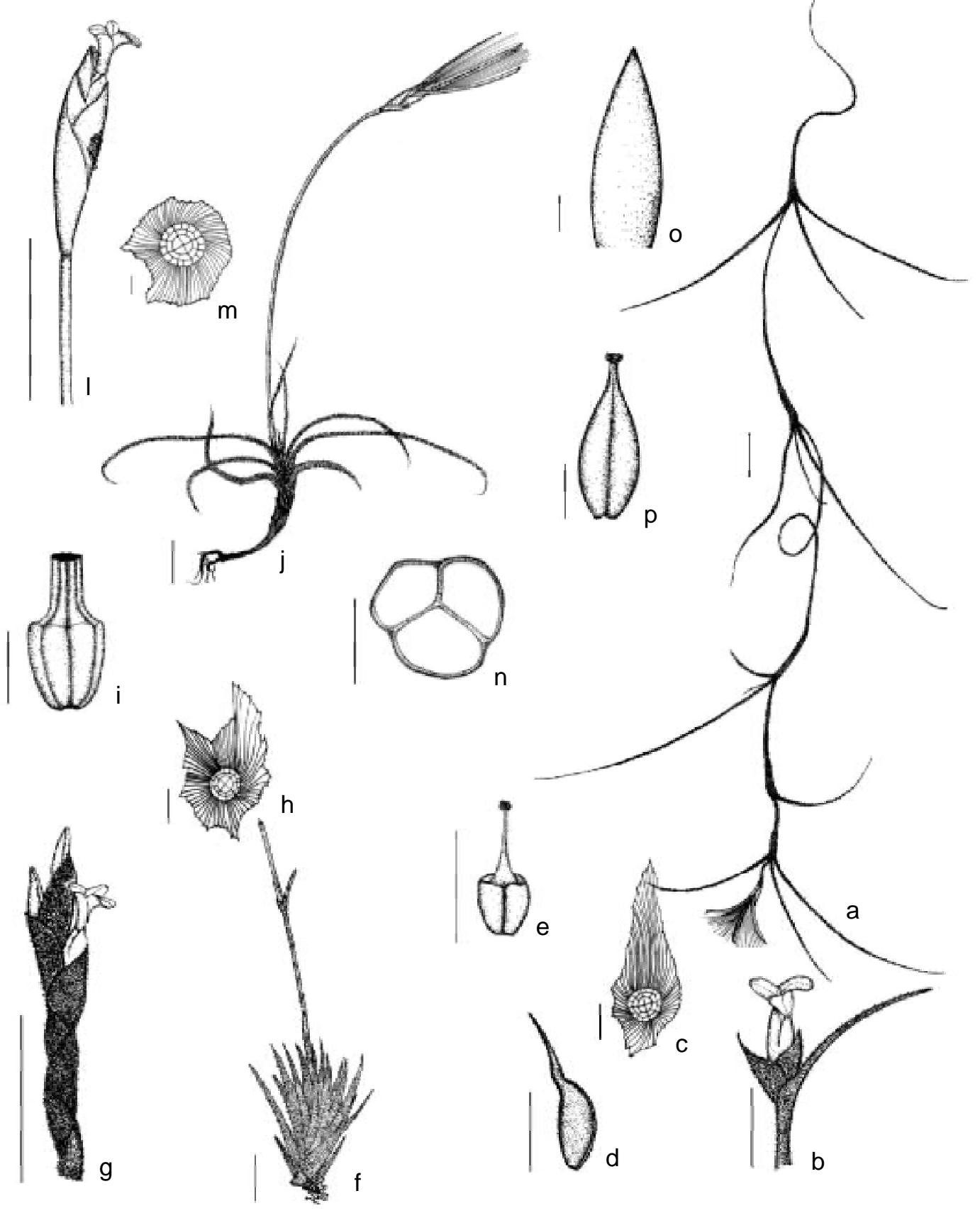

Figura 2 - Tillandsia usneoides - a. Hábito; b. ramo florido; c. escama; d. bráctea floral; e. gineceu (Agra 4228). T. loliacea - f. hábito; g. inflorescência; h. escama; i. gineceu (Agra 4660). T. recurvata - j. hábito; 1. inflorescência; m. escama; n. corte transversal do fruto; o. bráctea floral; p. ovário (Baracho s.n., JPB 21979). (Escalas: a, b, f, g, j, 1, $\mathrm{n}=1 \mathrm{~cm} ; \mathrm{d}, \mathrm{e}=3 \mathrm{~mm} ; \mathrm{i}, \mathrm{d}, \mathrm{e}=1 \mathrm{~mm} ; \mathrm{c}, \mathrm{h}, \mathrm{m}=83 \mu \mathrm{m})$. 
5. Tillandsia loliacea Mart. ex Schult. \& Schult. f., Syst. veg. 7: 1204. $1830 . \quad$ Fig. 2 f-i

Planta 5-8 cm alt., epífita ou rupícola; raízes presentes, rigídas. Folhas polísticas, fortemente cinéreas, imbricadas, eretas; lâmina $1-2,9 \mathrm{~cm}$ de compr., triangular, crassas, cinérea, ápice atenuado; bainha 2-4 mm compr., indistinta da lâmina, membranácea, translúcida. Escapo ereto, 2,5-5 cm compr.; brácteas escapais elípticas, 7$15 \times 3-4 \mathrm{~mm}$, curto caudadas, ápice ereto, imbricadas, cinéreas. Inflorescência em espiga simples, excedendo as folhas, 1-2 cm de compr.; brácteas florais 5-6 ×4-5 mm, oval-elípticas, agudo no ápice, cinéreas, menores que as sépalas. Sépalas subconatas, ca. $7 \times 2 \mathrm{~mm}$, elípticolanceoladas, ecarenatas, glabras, ápice acuminado. Pétalas ca. $8 \times 1,5 \mathrm{~mm}$ compr., amarela, linear, ápice rotundo; estames inclusos, ca. 4 mm de compr., soldados na base do ovário; filetes cilíndricos; ovário ca. 1,2 mm compr., suboboval; estilete ca. $1 \mathrm{~mm}$, subtriangular; estigma simples-ereto. Cápsula 2,1-3,7 cm compr.; valvas retas na deiscência; sementes 2 mm, apêndices 1,5-3 cm compr., plumosos.

Tillandsia loliacea é uma espécie da América do Sul ocorrendo no Peru, Brasil, Bolívia, Paraguai e Argentina (Smith \& Downs 1977). Na Paraíba, T. loliacea foi encontrada no agreste, matas serranas e na caatinga, ocorrendo entre 400 a 1.100 m de altitude. É uma espécie pouco coletada, provavelmente devido ao pequeno porte da planta, que não ultrapassa $8 \mathrm{~cm}$ de altura. Foi coletada com flores em janeiro, agosto e setembro. E em frutificação em agosto e setembro.

Material examinado: BRASIL. PARAÍBA: Maturéia, Pico do Jabre, 18-21.I.1998, fl., M. F. Agra et al. 4660 (JPB); Nazarezinho, Cantil, 2.VIII.1982, fl. e fr., Sousa et al. 5374 (JPB); Ingá, Pedra do Ingá, 27.IX.1992, fl., O. T. Moura 5412 (JPB); Juazerinho, 25.VI.1983, L. P. Xavier 5521 (JPB); São Gonçalo, Sítio Terra Nova, 22.VI.1999, O. T. Moura s.n. (JPB 24896); Serra Branca, Serra Branca, na base do inselberg, 4.IV.1996, M. F. Agra et al. 3554 (JPB); Sousa, 23.V.1936, P. V. Luetzelburg s.n. (IPA 47555).
6. Tillandsia polystachia (L.) L., Sp. pl. (2)1: 410. 1762.

Fig. 4 e-j

Planta 12-82 cm alt., epífita; caule inconspícuo a conspícuo; raízes presentes, rígidas. Folhas polísticas, cinéreo-esverdeadas, imbricadas; lâmina 6-30 cm compr., triangularlanceolada, ápice longamente atenuado; bainha 2-11 × 1,3-7,5 cm, indistinta. Escapo ereto, 3,5$33 \mathrm{~cm}$; brácteas do escapo oblongo-acuminadas, 7-27 × 1-3,8 cm, imbricadas, cinéreoesverdeadas. Inflorescência em espiga simples, 5-35 cm compr., excedendo as folhas; brácteas florais ca. 2,4 × 1,2 cm, vináceas, ovais, ápice apiculado, ultrapassando as sépalas. Sépalas conatas, 1,8 ×0,6 cm, elíptico-lanceoladas, carenadas, glabras, ápice agudo. Pétalas ca. $4 \times$ $0,6 \mathrm{~cm}$, linear, ápice subagudo a rotundo, lilases; estames exsertos, ca. 4,5 cm compr., soldados à base do ovário, livres entres si; filetes cilíndricos, roxos; ovário ca. $5 \mathrm{~mm}$ compr., oval-elíptico; estilete 4-4,5 cm, cilíndrico; estigma espiralconduplicado. Cápsula 2,3-3,7 cm de compr., valvas retorcidas na deiscência; sementes 2-3 mm compr., apêndices 1,5-2,9 cm compr., plumosos.

Tillandsia polystachia apresenta ampla distribuição, ocorrendo no sul da América do Norte (sul dos Estados Unidos e México), América Central, Caribe e América do Sul (Colombia, Equador, Venezuela e Brasil). Esta espécie tem sido registrada principalmente nas matas serranas da Paraíba. É uma planta de grande efeito ornamental, apresentam inflorescências com brácteas foliáceas verdes, que contrastam com a corola lilás das flores. Foi coletada com flores em dezembro e com frutos de julho a agosto.

Material examinado: BRASIL. PARAÍBA: Gurinhém, Serra do Cajá, 27.VIII.1998, fr., G. S. Baracho s.n. (JPB 21984); Maturéia, Pico do Jabre, 27-29.IX.1997, fl. e fr., M. F. Agra et al. 4209 (JPB); 18.I.1997, M. F. Agra et al. 3908 (JPB); 18.I.1997, M. F. Agra et al. s.n. (JPB 21748); 18. VII.1997, fr., M. F. Agra et al. 4118 (JPB); Queimadas, Serra do Bodopitá, 8.XII.1998, fl., G. S. Baracho s.n. (UFP 22814). 


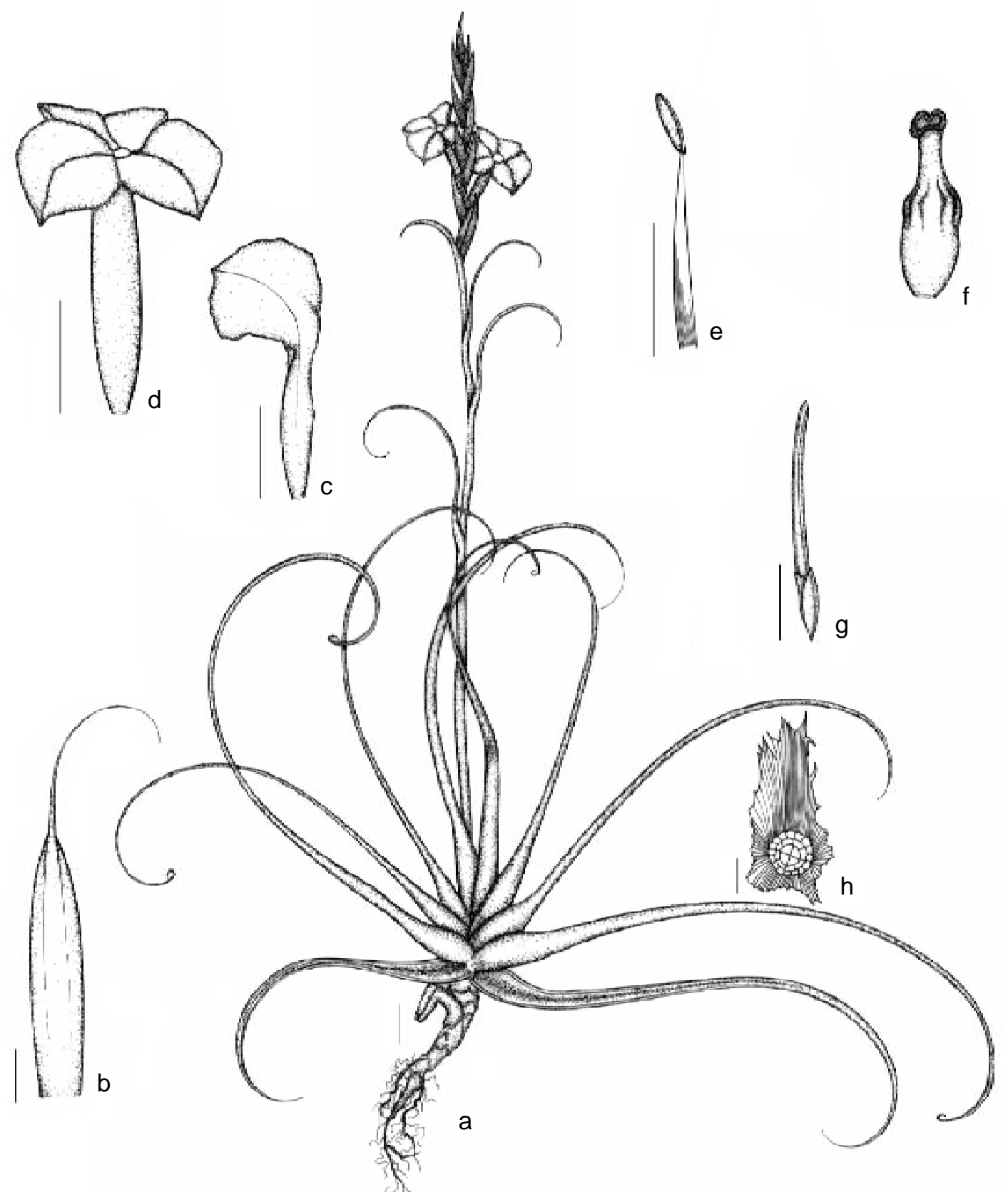

Figura 3 - Tillandsia streptocarpa - a. hábito; b. bráctea do escapo; c. pétala; d. flor; e. estame; f. gineceu; g. fruto; h. escama (Agra 4573). (Escalas: a, b, c. d, $g=1 \mathrm{~cm} ; \mathrm{e}, \mathrm{f}=3 \mathrm{~mm} ; \mathrm{h}=83 \mu \mathrm{m}$ ).

7. Tillandsia recurvata (L.)L., Sp. pl. ed. 2 1:410. 1762.

Fig. 2 j-p

Planta 8-12 cm alt., epífita ou rupícola; caule inconspícuo; raízes presentes, rígidas. Folhas dísticas, fortemente cinéreas, recurvadas; lâmina 4,3-5 cm compr., aciculada, cinérea, ápice agudo; bainha 4-5,5 × 3-4 mm, levemente distinta, membranácea. Escapo Rodriguésia 57 (1): 47-61. 2006 ereto, 3,5-8,5 cm compr., bracteado. Inflorescência em espiga simples, excedendo as folhas, $1-1,5 \mathrm{~cm}$ compr.; brácteas florais ca. 7,5-8 × 3-3,5 mm, vináceas a cinéreas, elíptico-lanceoladas, ápice agudo, menor que as sépalas. Sépalas subconatas na base, $2 \times$ $7,5 \mathrm{~cm}$, elípticas, carenadas, glabras, ápice acuminado. Pétalas ca. $9 \times 1,2 \mathrm{~mm}$, linear, ápice 
rotundo, lilases; estames inclusos, ca. 4,5 mm compr., soldados na base do ovário; filetes cilíndricos; ovário ca. 3 mm compr., subcilíndrico; estilete 0,8-1 mm compr., cônico; estigma simples-ereto. Cápsula 2,3-2,6 cm compr., valvas retas na deiscência; sementes $2 \mathrm{~mm}$ compr., apêndices 1,8-2 cm compr., plumosos.

Tillandsia recurvata apresenta ampla distribuição na América tropical, ocorrendo no Sul da América do Norte, América Central, Caribe e América do Sul (Smith \& Downs 1977). Na Paraíba, T. recurvata tem sido encontrada em todos os tipos de ecossistemas, sendo abundante nos Cariris Velhos, a área de menor índice pluviométrico do estado. Foi coletada com flores em janeiro, maio e setembro, e com frutos em julho, setembro e dezembro.

Material examinado: BRASIL. PARAÍBA: Boa Vista 27-29.IV.1994, M. F. Agra et al. 2932 (JPB); Cabaceiras, 29-30.V.1994, fl., $M$. F. Agra et al. 3563 (JPB); Sumé, 2930.I.1994, fl., M. F. Agra et al. 2807 (JPB); Aroeiras, 24-27.IX.1994, M. F. Agra et al. 3281 (JPB); Campina Grande, distrito de São José da Mata, 23.VI.1996, M. F. Agra 3402 (JPB); M. F. Agra s.n. (JPB 21581); 23.VI.1990, M. F. Agra s.n. (JPB 19332); São João do Cariri, 22-3.X.1993, M. F. Agra et al. s.n. (JPB 20033); São João do Cariri, 22.V.1997, G. Luna s.n. (JPB 22945); Cabaceiras, 29.VI-1.VII.1993, M. F. Agra et al. s.n. (JPB 20035); Areia, 11.IV.1986, O. T. Moura s.n. (JPB 15890); Ingá, 27.IX.1982, fl. e fr., O. T. Moura 5411 (JPB); Umbuzeiro, 13.XI.1984, Silva 6507 (JPB); Gurinhém, 27.VII.1998, fr, G. S. Baracho et al. s.n. (UFP 21979); Queimadas, 08.XII.1998, fr., G.S. Baracho et al. s.n. (UFP 22813); Cacimba de Dentro, 27.VII.1998, fr., G. S. Baracho et al. s.n. (UFP 21432).

\section{Tillandsia streptocarpa Baker, Jour. Bot.} London 25. 241. 1887.

Fig. 3 a-h

Planta 8,5-35 cm alt., epífita ou rupícola; caule conspícuo; raízes presentes, rígidas. Folhas polísticas, cinéreas, não imbricadas, fortemente recurvadas; lâmina $6,5-27 \mathrm{~cm}$ compr., triangular-linear, fortemente cinérea, ápice aciculado subespiralado, levemente caudadas; bainha ca. 1-1,8 cm compr., bem distinta da lâmina, membranácea. Escapo ereto, 6-17 cm compr.; brácteas oval-elípticas a elíptico-lanceoladas, 2-14 × 0,4-0,9 cm, imbricadas, caudadas, cinéreas. Inflorescência em espiga composta, raro simples, excedendo as folhas, 2,5-12 cm compr.; brácteas florais 1,8-0,6 cm compr., elíptico-lanceoladas, ápice acuminado, cinéreas. Sépalas subconatas, 1,3 $\times 0,6 \mathrm{~cm}$, elíptico-lanceoladas, ecarenadas, glabras, ápice agudo. Pétalas ca. $2 \times 0,6 \mathrm{~cm}$, orbicular, ápice obtuso, cerúleas; estames inclusos, $7 \mathrm{~mm}$ compr., soldados na base do ovário; filetes delgados, compressos; ovário ca. 3 mm compr., oval-elíptico; estilete 0,2-0,22 mm compr., cilíndrico; estigma espiralconduplicado. Cápsula 3,2-4,7 cm compr., valvas retas na deiscência; sementes $2-3,5 \mathrm{~mm}$ compr., apêndices 2,8-3,7 cm compr., plumosos.

Espécie exclusiva da América do Sul, ocorrendo na Bolívia, Brasil e Paraguai. No Brasil, ocorre desde o Nordeste até o Paraná (Smith \& Downs 1977), habitando áreas de campo rupestre, cerrado, restinga e caatinga. Na Paraíba T. streptocarpa foi coletada, principalmente, na caatinga, crescendo em afloramentos rochosos, graníticos e gnáissicos. Floresce em março, setembro e outubro. Frutifica em janeiro e setembro.

Material Eeaminado: BRASIL. PARAÍBA: Serra Branca, Serra Branca, 04.IV.1996, fl., $M$. F. Agra et al. 3546 (JPB); Cabaceiras, 29.VII1.VIII.1993, M. F. Agra et al s.n. (JPB 20036); Boa Vista, 22.VI.1996, M. F. Agra et al. 3837 (JPB); São João do Cariri, 29- 31.X.1993, M. F. Agra et al. 2364 (JPB); Maturéia, Pico do Jabre, 18.I.1996, fl., M. F. Agra et al. 3912 (JPB); 27-29.IX.1997, fl., M. F. Agra et al. 4.216 (JPB); 19-20.X.1997, fl., M. F. Agra et al. 4573 (JPB); 27-29.IX.1997, fr., M. F. Agra et al. 4233 (JPB); São João do Cariri, 18.IX.1997, G. Luna s.n. (JPB 24903); Soledade, 27.I.1971, Carvalho 3484 (JPB); Queimadas, 08.XII.1998, G. S. Baracho s.n 


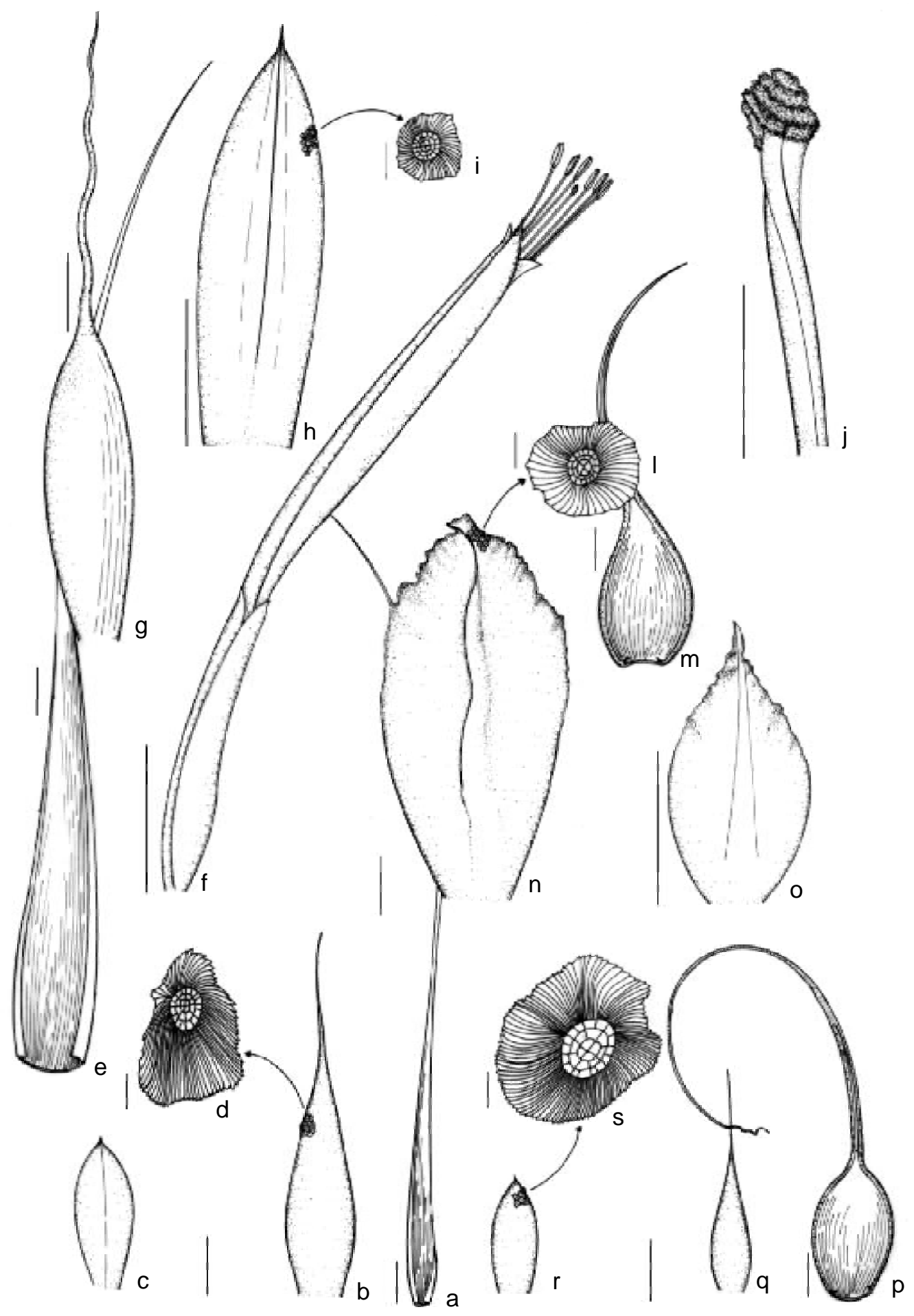

Figura 4 - Tillandsia juncea - a. folha; b. bráctea do escapo; c. bráctea floral; d. escama (Baracho s.n., JPB 21980). T. polystachia - e. folha; f. flor; g. bráctea do escapo; h. bráctea floral; i. escama; j. estigma (Baracho s.n., JPB 22814). T. kegeliana - 1. escama; m. folha; n. bráctea floral; o. bráctea do escapo (Andrade-Lima 67-4998). T. bulbosa - p. folha; q. bráctea do escapo; r. bráctea floral; s. escama (Félix s.n., JPB 15659). (Escalas: a, b, c, e, f, g, h, m, p, q, r = 1 cm; n, $\mathrm{o}=5 \mathrm{~mm} ; \mathrm{j}=3 \mathrm{~mm} ; \mathrm{d}, \mathrm{i}, \mathrm{l}, \mathrm{s}=83 \mu \mathrm{m})$. 
(JPB 22812); Cabaceiras, 1.VII.1993, M. F. Agra et al. s.n. (JPB 20036); Serra Branca, 4.IV.1996, fl., M. F. Agra et al. s.n. (JPB 21600).

9. Tillandsia stricta Sol. ex Sims, Bot. Mag. 37: pl. 1529.1813.

Fig. $1 \mathrm{~m}-\mathrm{n}$

Planta 13-15 cm alt., epífita; caule inconspícuo; raízes presentes, rígidas. Folhas polísticas, cinéreas, imbricadas, eretas; lâmina 2-11 cm compr., triangular-lanceoladas, cinérea, ápice filiforme; bainha 1-1,5 cm compr, pouco distinta da lâmina, membranácea. Escapo ereto, 4-5 cm compr.; brácteas subelípticas a elípticas, 5-6×0,4-0,6 cm, curto caudadas, ápice ereto, imbricadas, cinéreas. Inflorescência em espiga, simples, excedendo as folhas, $8 \mathrm{~cm}$ compr.; brácteas florais 2,2-2,4 $\times 0,6-0,9 \mathrm{~cm}$, oval-elípticas, ápice cuspidado, cinéreas, ultrapassando as sépalas. Sépalas conatas na base, 1,1-1,2 ×0,3-0,4 cm, elípticas, carenadas, glabras, ápice acuminado. Pétalas púrpuras, ca. 1,7 ×0,4 cm, espatuladas, ápice arredondado; estames inclusos, ca. $1,3 \mathrm{~cm}$ compr., livres; filetes plicados; ovário ca. $3 \mathrm{~mm}$ compr., subovóide; estilete 1,2-1,3 cm compr.; estigma simples-ereto. Frutos não vistos.

De acordo com Smith \& Downs (1977), T. stricta possui distribuição restrita ao nordeste da América do Sul, ocorrendo desde o Brasil até o Paraguai. Na Paraíba a espécie é conhecida por uma coleta, realizada em um remanescente de mata atlântica, sendo aqui referida pela primeira vez para o estado. Floresce em agosto.

Material examinado: BRASIL. PARAÍBA: Mamanguape, Estação Ecológica, 17.VIII.1988, fl., L. P. Felix \& A. Miranda s.n. (JPB 15660).

10. Tillandsia tenuifolia var. surinamensis (Mez) L.B.Sm., Phyt. 8: 220. 1962. Fig. 1. a-e

Planta 14-25 cm alt., epífita ou rupícola; caule conspícuo; raízes presentes, rígidas. Folhas polísticas, verdes, imbricadas, eretas; lâmina 2,5-8 cm compr., triangular, ápice acuminado; bainha 1,5-2 cm compr., membranácea, pouco distinta da lâmina. Escapo ereto ou sub-ereto, 3-6 cm compr.; brácteas elípticas a sub-ovais, 5-1 ×3-6 mm, curto caudadas, ápice ereto, imbricadas, verdes. Inflorescência em espiga, simples, excedendo as folhas, $10 \mathrm{~cm}$; brácteas florais róseas, 0,7-2×0,3-0,7 cm, oval-elípticas, ápice levemente cuspidado, ultrapassando as sépalas. Sépalas conatas, $0,8-1 \times 0,15-0,2 \mathrm{~cm}$, elíptico-lanceoladas, carenadas, glabras, ápice acuminado. Pétalas alvas, ca. 1,2 × 0,3 cm, espatuladas, ápice obtuso; estames inclusos, ca. $1,3 \mathrm{~cm}$ compr., três livres e três epipétalos, soldados na altura da unha pétala; filetes plicados; ovário ca. $3 \mathrm{~mm}$ compr., ovóide; estilete 1-1,3 cm compr; estigma simplesereto. Frutos não vistos.

Tillandsia tenuifolia var. surinamensis é uma variedade da América do Sul, ocorrendo desde a Venezuela até a Argentina. Neste estudo registrou-se a presença desta espécie num remanescente de mata atlântica e numa mata serrana. Entretanto, a espécie também foi registrada por Smith \& Down (1977) para as microrregiões dos Cariris Velhos e Agreste da Borborema. Possuem grande efeito ornamental com brácteas florais róseas que contrastam com suas pétalas alvas. Amostras floridas foram coletadas em maio, setembro e outubro.

Material examinado: BRASIL. PARAÍBA: Maturéia, Pico do Jabre, 27-29.IX.1997, fl., M. F. Agra et al. 4292 (JPB); 19-20.X.1997, fl., M. F. Agra et al. 4564 (JPB); Sapé, Fazenda Pacatuba (RPPN), 6.IV.2001, fl., E. César s.n. (JPB 28267).

11. Tillandsia usneoides (L.)L., Sp. pl. 2. 411. 1762.

Fig. 2 a-e

Planta pendente, com ramos até $15 \mathrm{~m}$ compr., epífita; raízes ausentes. Folhas dísticas, cinéreas, imbricadas; lâmina 4,7-7 cm compr., sub-cilíndrica, aciculada, suculenta, cinérea, densamente lepidota, levemente recurvada, ápice aciculado; bainha 8-10×3-4 mm, pouco distinta da lâmina, membranácea. Escapo ausente; brácteas florais ca. $5 \times 3 \mathrm{~mm}$, suborbiculares, apiculadas, marrons a vináceas no ápice. Flores solitárias, ca. de 1,5 cm. Sépalas 
subconatas, $7 \times 2 \mathrm{~mm}$, elíptico-lanceoladas, carenadas, glabras, ápice agudo a apiculado. Pétalas ca. $9 \times 1,2 \mathrm{~mm}$, linear, verdeamareladas, ápice agudo; estames inclusos, 5 mm compr., soldados na base do ovário; filetes cilíndricos; ovário ca. 1,5 mm compr., suboboval; estilete 1,4-1,5 mm compr., robusto; estigma ereto-simples. Cápsula 1,6$2 \mathrm{~cm}$ compr., valvas retorcidas na deiscência; sementes 2 mm compr., apêndices ca. 1,5$1,8 \mathrm{~cm}$ compr., plumosos.

Espécie com ampla distribuição, ocorrendo desde o Sul da América do Norte, Caribe, América Central até o Sul da América do Sul. Na Paraíba T. usneoides só foi encontrada em uma área de mata serrana, há mais de $1.000 \mathrm{~m}$ de altitude, habitando o topo de árvores onde formam grandes cortinas, provavelmente pela grande umidade atmosférica na área. Foi coletada com frutos em março, abril e setembro.

Material examinado: BRASIL. PARAÍBA: Maturéia, Pico do Jabre 27-29.IX.1997, fr., M. F. Agra et al. 4228 (JPB); 18.I.1997, M. F. Agra et al. 3913 (JPB); 27-19.IX.1997, M. F. Agra et al. 4219 (JPB); 16.IV.1993, fr., M. F. Agra et al. 2002 (JPB); 25-27.II.1997, M. F. Agra et al. 2659 (JPB); 25-27.III.1994, fr., M. F. Agra et al. 2589 (JPB).

\section{Discussão e Conclusões}

Na Paraíba as espécies de Tillandsia são encontradas nos diferentes tipos vegetacionais do estado, ocorrendo desde a mata atlântica até a caatinga. A maioria das espécies estudadas ocorre no domínio da caatinga, onde foram registradas nove espécies, que corresponde a $81,8 \%$ do total, ocorrendo tanto na caatinga propriamente dita, como nos enclaves de matas serranas.

O Pico do Jabre destacou-se como a mata serrana com maior diversidade, onde foram encontradas sete táxons ( $T$. recurvata, T. streptocarpa, T. usneoides, T. gardneri, T. polystachia, T. loliacea e T. tenuifolia var. surinamensis), que correspondem a $63,6 \%$. Outra área de grande diversidade foi registrada para os "brejos de altitudes", no município de Areia, com seis espécies, representando cerca de $54,5 \%$ do total para o estado.

Com relação às áreas de Mata Atlântica, foram coletadas T. bulbosa, T. kegeliana, T. gardneri, T. polystachia, $T$. recurvata, $T$. stricta, $T$. juncea, $T$. tenuifolia var. surinemensis, T. loliacea e T. usneoides, representando um percentual de $91 \%$ dos táxons ocorrentes no estado, sendo este o ecossistema com a maior diversidade para o gênero Tillandsia na Paraíba.

Tillandsia gardneri e $T$. recurvata apresentaram a distribuição mais ampla, sendo encontradas em elevações de 10 a $1.200 \mathrm{~m}$ de altitude, nos diferentes tipos de vegetação do estado, classificados por Carvalho \& Carvalho (1985) como mata úmida, agreste, matas serranas, "brejos de altitudes" e caatinga. Tillandsia stricta e T. bulbosa tiveram a menor distribuição, sendo encontradas apenas em áreas de mata úmida do litoral paraibano, estas constituem novas referências para o estado. Nenhum dos táxons estudados apresentou distribuição restrita ao estado.

Quanto a forma de vida, prevaleceu o epifítico, registrado para $63 \%$ das espécies encontradas: T. bulbosa, T. gardneri, T. juncea, T. kegeliana, T. polystachia, T. stricta e $T$. usneoides. Espécies facultativas, ocorrendo como epífitas e rupícolas, corresponderam a $36 \%$, T. loliacea, $T$. recurvata, $T$. streptocarpa e $T$. tenuifolia var. surinemensis. Nenhuma espécie apresentou-se exclusivamente rupícola.

Destacaram-se como os caracteres mais importantes para o reconhecimento das espécies a filotaxia e as morfologias do androceu e do pistilo.

O gênero Tillandsia está representado na área por cerca de 1,7\% das espécies conhecidas. Apesar de sua baixa diversidade, em relação ao gênero como um todo, observouse que a maioria das espécies ocorre em populações, com grande número de indivíduos, seja como epífita em uma mesma árvore, ou rupícola em afloramentos rochosos. Esse número elevado de indivíduos formando 
populações extensas, provavelmente, tem contribuído para uma estimativa de maior diversidade para o gênero no Nordeste do Brasil, principalmente para a caatinga.

Em comparação com levantamentos realizados em outros estados do Nordeste, verificou-se que o gênero Tillandsia encontrase bem representado na Paraíba. Mayo et al. (1995) registraram a presença de quatro espécies para o Pico das Almas, destas apenas $T$. sprengeliana Klotzsch não foi encontrada na Paraíba. Siqueira-Filho (2002) registrou a ocorrência de 16 espécies para Pernambuco, das quais 11 também foram registradas para a Paraíba $(68,7 \%)$. Já Wanderley \& Sousa (2002), citam para a caatinga paraibana oito espécies.

\section{Agradecimentos}

Os autores agradecem ao Dr. Marcelo Sobral, diretor do Laboratório de Tecnologia Farmacêutica, pelo apoio pessoal e institucional; aos curadores dos herbários EAN, JPB, IPA e UFP, pelo livre acesso as suas instalações e empréstimo de exsicatas; Dr. Jnanabrata Bhattacharyya, pela revisão do abstract; Dr. Gregory Browm, pelo apoio com a bibliografia; Dr. George S. Baracho e Dra. Rafaela C. Forzza, pela revisão do manuscrito, críticas e sugestões. Ao Conselho Nacional de Pesquisa e Desenvolvimento Científico $(\mathrm{CNPq})$ pela bolsa PQ de M. F. Agra.

\section{REFERÊNCIAS BIBLIOGRÁFICAS}

Agra, M. F. \& Barbosa, M. R. V. 1996. Lista anotada das Asteraceae no estado da Paraíba. Revista Nordestina de Biologia 11(2): 73-86.

Barbosa, M. R. V.; Mayo, S.J; Castro, A. A. J. F.; Frietas, G. L.; Pereira, M. S.; Neto, P. C. G. \& Moreira, H. M. 1996. Checklist preliminar das angiospermas. In: Sampaio, E. V. S. B; Mayo, S. J. \& Barbosa, M. R. V. (eds). Pesquisa botânica nordestina: progresso e perspectivas. SBB, Recife. Pp. 253-415.
Brown, G. K. \& Gilmartin, A. J. 1989. Stigma types in Bromeliaceae - a systematic survey. Systematics Botany 14(1): 110132.

Cabral, S. \& Agra, M. F. 1999. Flora da Paraíba: Olacaceae Mirb. ex DC. Revista Nordestina de Biolologia 13(1.2): 1-11.

Carvalho, F. A. \& Carvalho, M. G. 1985. Vegetação. In: Atlas geográfico da Paraíba. Grafset. João Pessoa, PB. 99p.

Grant, J. R. \& Zijlstra, G. 1998. An anotated catalogue of the generic names of the Bromeliaceae. Selbyana 19(1): 91-121.

Leme, M. C. E. 1993. Bromélias na natureza. Marigo Comunicação Visual, Rio de Janeiro, RJ. 183p., il.

Luther, E. H. 2000. An alphabetical list of bromeliad binomials. 7 ed. The Marie Selby Botanical Gardens, Sarasota, Florida, USA. 143p.

Mayo, S. J.; Wanderley, M. G. \& Gouda, E. 1995. Bromeliaceae. In: Stannard, B. L. (ed.). Flora of the Pico das Almas, Chapada Diamantina, Bahia, Brazil. Royal Botanic Gardens, Kew. Great Britain. Pp. 649-659, fig. 41.

Mez, C. 1891-1894. Bromeliaceae. In: Martius, C. F. P. von; Eichler A \&. Urban I. (eds.), Flora brasiliensis. Munchen, Wien, Leipzig, 3(3): 173-634.

Pontes, R. A. \& Agra, M. F. 2001. Flora do Pico do Jabre, Paraíba, Brasil: Acanthaceae. Leandra 16: 51-60.

Radford, A. E.; Dickison, W. C.; Massey, J. R. \& Bell, C. R. 1974. Vascular plant systematics. Harper \& Row, New York. 891p.

Rocha, E. A. \& Agra, M. F. 2001. Lista anotada das Lamiaceae da Paraíba, Brasil. Revista Nordestina de Biologia 15(1): 71-75.

2002. Flora do Pico do Jabre, Paraíba, Brasil: Cactaceae Juss. Acta Botânica Brasilica 16(1): 15-21.

Siqueira-Filho, J. A. 2002. Bromélias em Pernambuco: Diversidade e aspectos conservacionistas. In: Taberelli, M. \& Silva, 
J.M.C. (eds). Diagnóstico da Biodiversidade de Pernambuco. Recife, PE, vol. 1. Pp. 219-227.

Smith, L. B. 1955. The Bromeliaceae of Brazil. Mary Vaux Walcott Fund for Publications in Botany. Washington. Smithsonian Miscellaneous Collections 126(1): 1-290.
Smith, L. B \& Downs, R. J. 1977. Tillandsioideae (Bromeliaceae). Flora Neotropica 14(2): 1492.

Wanderley, M. G. L. \& Sousa, G. M. 2002. Distribuição das espécies de Bromeliaceae na caatinga. In: Vegetação e Flora da Caatinga. Recife, PE. Pp. 121-122. 
